\title{
CONHECIMENTO E PRÁTICA EM SAÚDE COLETIVA: O DESAFIO PERMANENTE
}

\author{
Amélia Cohn *
}

\begin{abstract}
Este texto procura fazer uma reflexão, a partir da produção científica da Saúde Coletiva, da questão da articulação da política na e da Saúde Coletiva. Sob a forma de ensaio, busca-se trazer para a discussão tensões e impasses atuais que estão presentes no campo no sentido de instigar novos debates, contribuindo assim para uma revitalização da área. Relaciona-se, ainda, o "estado da arte" em dois momentos específicos: 0 da transição e 0 da consolidação democrática no país.
\end{abstract}

Este texto, sob a forma de ensaio, tem por objetivo trazer alguns elementos para a discussão sobre a produção do conhecimento na área da Saúde Coletiva e a atual conjuntura das práticas polfticas do setor. Busca-se resgatar, em grandes linhas, esse movimento do conhecimento e das práticas detectando-se algumas das principais tensões de ordem teórico-metodológica que o marcaram.

Fundamenta esse objetivo a percepção de que a produção do conhecimento na área apresenta, hoje, uma limitação no que diz respeito à sua capacidade de inovar questões e propor novas linhas de reflexão e novas temáticas.

* Docente do Departamento de Medicina Preventiva da Faculdade de Medicina da Universidade de São Paulo e pesquisadora do CEDEC. 
Cabe, no entanto, registrar que quanto a este último aspecto nota-se um movimento no sentido de se buscar coletar, sistematizar e analisar experiências concretas, de caráter mais micro, mas que acaba esbarrando nos antigos preceitos que vêm delineando a Saúde Coletiva enquanto um campo de práticas.

São abundantes os trabalhos que realizam uma sistematização da produção de conhecimento na área, em particular aqueles realizados por Everardo Duarte Nunes (1). Não é este o objetivo deste ensaio. Ao contrário, ele parte dessa produção, que inspirou as observações que se fazem a seguir.

O ângulo de análise que se privilegia aqui deriva de uma provocação do próprio Everardo $D$. Nunes ao solicitar uma reflexão sobre o tema da questão da politica na e da Saúde Coletiva. E é dessa perspectiva que se buscou rastrear algumas das principais tensões entre a prática do conhecimento e a prática polftica que vêm marcando a área, e que hoje se fazem sentir mais agudamente.

Uma primeira tensão reside entre os marcos de análise macro-estruturais e a análise institucional das politicas. Não é novidade afirmar que a área da Saúde Coletiva nasce e se desenvolve pela negação do saber hegemônico, acompanhando e de certa forma liderando a constituição desse campo de conhecimento na América Latina. Esse fato, no entanto, implica na incorporação do materialismo histórico enquanto modelo explicativo: categorias como capital e trabalho, e conceitos como classes sociais, contradição e luta de classes passam a nuclear a vastíssima produção dos anos 70 e 80 sobre a produção social do processo saúde/doença. No que diz respeito às análises das políticas de saúde, no entanto, a contrapartida da incorporação da perspectiva macro-estrutural histórica traduziu-se na predominância de pressupostos de natureza macro, e na utilização de um conceito de Estado de classes, no geral mal definido. 
Diante desse impasse, o conceito gramsciano de Estado ampliado revela-se como suficientemente elástico para dar conta da complexidade que significa debruçar-se sobre uma formação social capitalista, e mais ainda do capitalismo tardio, como a brasileira. A frequência da sua utilização nos estudos a respeito é um sintoma.

A essa dificuldade de articular a análise de caráter macro estrutural a análises de realidades especificas, e diga-se de passagem que esta é uma questão que desafia até hoje as ciências sociais, soma-se uma outra, que se constitui numa segunda tensão.

Esta diz respeito ao fato de às análises dos processos históricos das polfticas de saúde somarem-se proposições de caráter institucional e organizacional, e que têm origem em outro paradigma que não o marxista. Resta aqui a questão do desafio não enfrentado teórica e metodologicamente, mas sempre presente como um pressuposto, do conhecimento e das práticas como superação. De fato, aí reside uma das questões que exige ser enfrentada com a maior urgência para que a produção do conhecimento na área supere o círculo de ferro em que se encontra, possibilitando um novo salto de qualidade (2).

Essas tensões por sua vez estão, em grande medida, delineadas e determinadas por uma terceira, que consiste no fato de a prática polftica da reforma sanitária brasileira ter se constituído como o horizonte, e portanto os limites, da produção do conhecimento.

Entrelaça-se, aqui, a questão da política na e da Saúde Coletiva. Em outros termos, na medida em que existe uma articulação estreita entre a produção do conhecimento, concebida enquanto uma prática política, e a estratégia política real do movimento sanitário brasileiro, esta acabou por imprimir a marca àquela, que se 
configura, então, como um saber militante (3).

De fato, a Saúde Coletiva enquanto um campo de práticas acaba por assumir a marca do predomínio da polf́tica sobre o conhecimento. Este passa a ter o caráter histórico de fundamentação das práticas políticas que caracterizam o movimento sanitário brasileiro (4), pagando o preço que isso representa em termos de limitação à possibilidade de apontar novos horizontes e alternativas.

Não se deve, pois, ao acaso que se verifica uma vez mais a freqüência com que os conceitos gramscianos de guerra de posição e guerra de movimento são incorporados, nem a omissão de esforços para se identificar os distintos atores polfticos envolvidos no próprio movimento sanitário que não sejam aqueles identificados como as forças conservadoras contrárias a ele.

Já foi referido anteriormente que os impasses, ou as tensões, que se verificam na produção do conhecimento na área em parte se devem àqueles da própria área das Ciências Sociais: e aqui uma vez mais eles se fazem sentir. De fato, nos estudos sobre polfticas de saúde no Brasil, de forma mais acentuada quando seus autores são da própria área da Saúde Coletiva, verifica-se a presença da herança da produção intelectual de origem marxista sobre o Estado latino-americano. Norbert Lechner, da Flacso do Chile, chama a atenção para o fato de esses estudos enfocarem o Estado predominantemente pela sua função histórica de agente modernizador dessas sociedades, em detrimento de se engendrar esforços sobre sua compreensão teórica.

Compreende-se, assim, que um balanço da literatura a respeito revele um desequilíbrio entre a produção teórica sobre o capitalismo dependente, ou o capitalismo tardio, e o que viria a ser sua contrapartida no âmbito do Estado. Em outros termos, enquanto a indagação sobre a especificidade do capitalismo selvagem 
suscita uma farta produção intelectual, sua correspondente - vale dizer, o que caracterizaria o Estado em sociedades do capitalismo tardio - não vem sendo contemplada de forma satisfatória, ou sequer embrionária.

Em decorrência, verifica-se um relativo "esquecimento" do que vem a ser, no período mais recente, seguindo O'Donnell, um Estado burocrático-autoritário.

Salta-se, assim, para o debate da modernização versus pósmodernidade, incorporando-se a literatura pertinente e atual sobretudo no debate europeu, numa forte tendência de com ele acabar se importando de forma acrítica para nossas realidades, inclusive a brasileira, o debate dos países centrais sobre a crise do Welfare State, e com ele a crise de paradigmas. Tudo isso filtrado pela pósmodernidade em países onde grande parte da população sobrevive na situação de extrema pobreza. Registre-se, a respeito, a reflexão sobre o trabalho como categoria sociológica chave feita por Offe (5).

Nesse sentido, vale a pena lembrar aqui a observação de Faoro (6) acerca da modernização e da modernidade no Brasil e a questão nacional: enquanto a modernização foi concebida como tendo no Estado sua figura central e como um projeto cientffico de caráter positivista ("o povo padecendo a modernização"), a modernidade implica num processo inverso, isto é, da sociedade para o Estado, sendo nisso que consiste o atual desafio para nossa sociedade.

Mas essas tensões vão ganhando magnitude e tecendo uma trama que as entrelaça de forma a imprimir sua marca na produção intelectual, uma vez mais como uma prática eminentemente política, nessa área. Retorna-se, assim, à questão da articulação entre os níveis macro e micro de análise, o que ocupa aqui o que seria identificado como uma quarta ordem de tensões. 
De fato, dadas as tensões anteriormente identificadas, detecta-se uma forte tendência para se imputar nas análises dos acontecimentos de nivel micro um sentido determinado pelos macro processos enquanto marco explicativo central. Em decorrência, mais se atribui do que de fato se verifica um caráter progressista dos recursos humanos (ou da força de trabalho) que trabalham no setor público da saúde; depreende-se, por exemplo, sem que os dados reais o permitam, uma comunhão de interesses entre determinadas forças sociais e determinadas categorias profissionais, e que posteriormente acabam se revelando como não verdadeiras, etc.

Mesmo ciente do risco de exceder ao nivel da provocação, vale a indagação sobre até que ponto os preceitos e conceitos que regeram o movimento sanitário brasileiro, e the deram legitimidade cientffica e técnica, não reatualizam o ideário da modernização, que agora adentra sorrateiramente pela porta dos fundos. Caso contrário, como explicar o estabelecimento de uma passagem automática, que sustentou e fundamentou a estratégia da Reforma Sanitária brasileira, entre o nível macro de análise, o processo de transição democrática e a democratização da saúde?

Constituem sintomas dessa tensão não só a forma indefinida com que a questão do controle público, sinonimizado como controle social, é tratada, a insistência em trabalhar com antinomias - o público versus o privado; a centralização versus a descentralização; o estatal versus o público versus o privado e a democracia representativa versus a democracia direta -, como também a fluidez e nebulosidade com que os atores sociais envolvidos no processo figuram nas análises.

Apesar de a literatura mais recente evidenciar um movimento da pesquisa na área em direção aos fenômenos de caráter mais micro de análise, ainda continua a imperar o desconhecimento desses atores sociais, e por isso qualificados 
pelos marcos teóricos de nível macro de análise, e não por suas práticas concretas. Traduzindo Em outros termos, seria como se a concepção de história que norteia os analistas se sobrepusesse aos próprios atores sociais, tomados como sujeitos sociais coletivos dados a priori, e não como a sua prática concreta na teia social os constituindo enquanto tais.

Ora, como o marco predominante de análise é o materialismo histórico, gera-se al uma outra tensão: marcadas as análises pela conjuntura da transição democrática do pals, as atenções agora voltam-se para a saúde como direito do cidadão, e portanto como o aprendizado e o exercício cotidiano da cidadania. Mas as matrizes teóricas da categoria trabalho - e seu correlato, o conceito de classe social e do conceito de cidadania são radicalmente distintas. Em conseqüência, o desafio de articular os niveis macro e micro de análise acabam por gerar uma outra - quintatensão no nível analítico. Esta, no entanto, diferentemente das anteriores, pode vir a se constituir num dos núcleos de inovação e revitalização da área: a relação ou articulação, no nivel analitico, entre trabalho e cidadania.

Isso, por sua vez, remete à necessidade de se explicitar e qualificar de forma clara e precisa os interlocutores desses novos (porque recém descobertos na sua prática cotidiana) sujeitos sociais coletivos. Quando a ênfase recai sobre o Estado, de que Estado se trata - em termos teóricos e históricos. Quando a ênfase recai sobre os modos de acumulação de capital, como se dá essa articulação. E quando a ênfase recai sobre os aspectos de ordem administrativa e organizacional, qual sua relação com o Estado e quem são esses sujeitos sociais que implementam no cotidiano as políticas e práticas de saúde.

Mas se de um lado essas tensões acabam por se revelar, e de certa forma imprimir, um descompasso entre a produção do conhecimento das distintas 
áreas que compõem o campo da Saúde Coletiva, onde as de caráter teóricometodológico estão em nftida desvantagem sobre aquelas que em tese e enquanto propósito se configuram como mais práticas (7), de outro elas nos remetem a novos desafios. Estes são não só ditados pela atual conjuntura de consolidação de uma ordem democrática no país, como também de natureza teórico-metodológica.

\section{Revisitando antigas questões}

Diante desse diagnóstico de tensões, impasses e desafios que marca no atual momento a questão da polftica na e da Saúde Coletiva, faz-se necessário que se recoloquem determinadas questões, agora sob novo ângulo. A intenção, aqui, não está em responder problemas, mas tão somente levantar alguns deles que se apresentam na atual conjuntura, e que demandam respostas substantivas.

Se até o presente o movimento sanitário caracterizou-se por até certo ponto dar as costas para os setores populares organizados da sociedade, no geral já qualificados de antemão pelo marco teórico, será que atualmente não estaria havendo um movimento contrário, isto é, o movimento sanitário tendendo a dar as costas para o Estado? Seria necessário que se enfrentasse essa questão em termos de sua implicação de natureza teórico-metodológica sobre o produção do conhecimento e sobre sua capacidade de implementar e instrumentalizar as práticas especfficas do setor.

Daí decorre uma segunda questão pertinente à articulação da política na e da Saúde Coletiva. Uma coisa é essa articulação na conjuntura da transição democrática, onde a ênfase recai sobre a conquista de instituições polfticas democráticas; outra é a conjuntura da consolidação democrática , onde a ênfase 
recai sobre a efetivação dos preceitos constitucionais conquistados no momento anterior, mas agora do ângulo da democracia substantiva e social.

Em outros termos, isso significa que cabe hoje à área da Saúde Coletiva a conquista de sua maioridade; isto é, de um lado assumir sua especificidade pós período desenvolvimentista; e de outro, assumi-la pós período da transição democrática, onde agora cabe a ela mostrar sua especificidade frente às outras áreas e setores.

No primeiro caso, o que está em jogo é empreender esforços no sentido de conquistar efetiva legitimidade cientffica e acadêmica para a área, o que implica certamente em a própria área deixar de ser tão complacente consigo mesma. A herança do período desenvolvimentista consiste aqui em que a área social foi relegada a plano absolutamente secundário, na medida em que o império do ideário da modernização trazia consigo a ideologia do progresso social, cabendo agora enfrentar a questão da desigualdade social e seu impacto sobre as possibilidade de uma ordem democrática.

No segundo caso, o que está em jogo é a questão da busca de identidade da área enquanto um campo de conhecimento especffico, agora sem estar sob as sombras protetoras da luta pela transição democrática. Quando se diferencia Medicina Social e Saúde Coletiva, faz-se necessário especificar ambos os termos e a articulação entre eles. Essa parece constituir uma tarefa das mais urgentes, sob pena de se ganhar em amplitude e se perder em especificidade. Ademais, essa tarefa implica esforços no sentido de suplantar a marca da constituição desse campo de práticas cientificas e politicas (sem nunca dissociá-las, mas reconhecendo que são momentos especfficos de um mesmo processo) pela negação, e imprimir-lhe a marca propositada. Aí certamente o desafio maior residiria 
no primeiro termo, de caráter mais técnico.

Isso remete à indagação, fundamental na atual conjuntura, de qual a especificidade da saúde no interior do processo de construção e consolidação de uma ordem democrática no país em termos da democracia política e social.

Nesse sentido, há que se assumir que a Reforma Sanitária brasileira, enquanto um movimento especffico numa dada conjuntura, esgotou-se. Mas que se esgotou porque cumpriu seu ciclo, e nesse sentido foi exitosa. De fato, sua proposta consistiu em conquistar no âmbito das instituições polfiticas que seus princípios fossem contemplados, pré-requisito fundamental para avanços futuros. A contrapartida, porém, que se apresenta hoje consiste exatamente em buscar novos caminhos e novas questões que possibilitem alimentar o potencial inovador desse campo.

Em resumo, faz-se necessário que se assumam as heranças da Reforma Sanitária brasileira - a fragilidade de seus modelos explicativos, sua fragilidade enquanto processo polftico de efetivo enraizamento nas bases sociais e enquanto capacidade até o momento demonstrada de produção de modelos de práticas (portanto normativos) para além dos organizacionais - o que significa retornar à indagação básica, sob novas perspectivas, sobre qual a especificidade da saúde hoje.

Dentre essas novas perspectivas, e num movimento de conquista de sua especificidade, uma das questões centrais reside em enfrentar o fato de que até o presente este campo, ao enfatizar os processos sociais, acaba por vir perdendo sua individualidade enquanto área especifica de práticas de conhecimento e de práticas políticas, delegando ao horizonte dos processos sociais em curso a resolução de seus problemas especfficos. 
Cabe, portanto, indagar-se sobre por que o vazio que hoje se identifica nesse campo. Por que seus temas Não têm inovado, e até que ponto seus paradigmas trazem a possibilidade de inovação; e se eles estão em crise, ou se o que vem ocorrendo é, uma vez mais, a importação apressada das pulsações externas do debate intelectual.

À guisa de exemplo, vale o registro da facilidade e ligeireza com que os preceitos do neo-liberalismo tout court vem sendo importado, sem se indagar sobre a sua especificidade cabocla, o que encontra um caldo de cultura favorável na não diferenciação, por exemplo, entre o público e o estatal.

A busca da construção de um novo estatuto da identidade desse campo deve, portanto, enfrentar a tentação de não deixar que volte de forma dissimulada a importação de dogmas e modelos que não condizem com a nossa realidade. Esse movimento, por sua vez, implica em assumir que a incorporação de determinados autores presentes no debate intelectual, sobretudo da área das humanidades, seja feito com cautela no sentido de respeitar o rigor que merecem. Se num determinado momento os escritos de Marx sofreram sérios danos nessa importação, atualmente é necessário retomá-los em sua complexidade, ao mesmo tempo que é necessário cuidar para que o mesmo não ocorra, por exemplo, com os escritos de Habermas, para mencionar um autor dos mais citados.

Essas questões, no entanto, se não são específicas deste campo, mas aqui se fazem presentes de modo particular na exata medida em que as ciências sociais se constituiram num instrumental nuclear dele, a tarefa que se apresenta consiste em, da ótica da sua especificidade, revisitar - atualizando - os velhos paradigmas, o que significa repensar a saúde enquanto um setor especffico das políticas públicas, indagando, ao mesmo tempo, sobre a viabilidade (e implicações) 
de se pensar o planejamento social sem um projeto especffico para a sociedade para além do ideal democrático. Dito em outras palavras, repensá-la num confronto entre utopia e realidade.

Tudo isso, no entanto, remete a tarefas que não são de pequena complexidade. Dentre elas, buscar articular os niveis macro e micro de análise sem que as próprias ciências sociais disponham de metodologia para tanto; enfrentar a questão de como voltar-se para processos especfficos como objeto de análise de forma a apresentarem capacidade explicativa, sem no entanto pulverizá-los em suas particularidades, e sem que se detenha no mero nivel descritivo; como buscar o rigor teórico-metodológico nos distintos modelos de explicação sem recair na sua importação como uma mera somatória de distintos autores; e finalmente, como equacionar a questão fundamental de apreender as novas formas de articulação entre economia e politica, entre o nacional e o internacional, entre a globalização e a localização, etc.

Mas se as reflexões feitas aqui só foram possíveis pela vitalidade que este campo vem demonstrando desde sua constituição, o que lhe dá um papel de destaque no interior da América Latina, há que se reconhecer que hoje ele vem demandando, exatamente por ser um campo de práticas, inovações que lhe sirvam de alavanca para o avanço do conhecimento. Estas, por sua vez, só ocorrerão na medida em que haja um confronto do ideário com a realidade, ou das utopias com a realidade, sob a perspectiva agora propositada, sob pena de a Saúde Coletiva sufocar-se, enquanto questão da política no e do campo, sob a égide da ordem vigente, tendo no entanto como utopia a construção de uma nova ordem social e politicamente democrática. 


\section{NOTAS}

(1) - Nunes, E.D. - "As ciências sociais em saúde: reflexões sobre as origens e a construção de um campo de conhecimento", Saúde e Sociedade, ne 1/1, pp.59-84, 1992.

(2) - É instigante, neste sentido, o texto de Oliveira, J.A. - "Reformas e Reformismo: para uma teoria política da Reforma Sanitária (ou, reflexões sobre a Reforma Sanitária de uma perspectiva popular)", in: Costa, N.R. et al. - Demandas Populares, Políticas Públicas e Saúde, vol I, $1^{a}$ edição, Petrópolis, Editora Vozes, 1989; pp.13-44.

(3) - Cohn, A. -" Caminhos da Reforma Sanitária", Lua Nova, n² 19, pp.123-140, 1989.

(4) - A literatura sobre a Reforma Sanitária brasileira é vastíssima e bastante conhecida e divulgada, o que dispensa citações. Mas é o seu conjunto que inspira estas reflexões.

(5) - Offe, C. - Capitalismo Desorganizado, S. Paulo, Editora Brasiliense, 1989.

(6) - Faoro, R. -" A Questão Nacional: a modernização", Estudos Avancados, USP/S. Paulo, 1992, pp. 7-22.

(7) - Retoma-se, aqui, o texto de Nunes, E.D., op. cit. 